\title{
The neurobiology of the stress-resistant brain
}

\author{
MONIKA FLESHNER ${ }^{1}$, STEVEN F. MAIER ${ }^{2}$, DAVID M. LYONS ${ }^{3}$, and MURRAY A. RASKIND 4 \\ ${ }^{1}$ Department of Integrative Physiology, University of Colorado, Boulder, CO, USA \\ ${ }^{2}$ Department of Psychology and Neuroscience, University of Colorado, Boulder, CO, USA \\ ${ }^{3}$ Department of Psychiatry and Behavioral Sciences, Stanford University, Stanford, CA, USA \\ ${ }^{4}$ Department of Psychiatry and Behavioral Science, University of Washington School of Medicine, \\ Seattle, WA, USA
}

\begin{abstract}
The 2010 Neurobiology of Stress Workshop brought together scientists from all over the world to share and discuss their results from studies examining the consequences of acute, repeated, and chronic stressor exposure on health and disease. Session IV entitled "The neurobiology of the stress-resistant brain" explored how we can intervene to promote stress resistance and stress resilience. Four scientists, who explore this topic from unique and convergent perspectives, presented their experimental results derived from studies in rat (Fleshner and Maier), non-human primates (Lyons), and human (Raskind). Summaries of each presentation, supporting publications, and overall take-home messages from the session are presented.
\end{abstract}

\section{Keywords}

Stress resistance; stress resilience; exercise; controllability; neurogenesis; post-traumatic stress disorder

\section{Introduction}

Below is a summary of the lectures presented at the 2010 Stress Workshop held in Boulder, Colorado, in the symposium entitled "The neurobiology of the stress-resistant brain." Before presenting the synopses of the presentations, we offer definitions of stress resistance and stress resilience. These concepts have been defined elsewhere and vary depending on the scientific field. The definitions offered below harmonize with clinical definitions.

The cascade of responses that comprise the acute stress response is supremely adaptive under most circumstances. For example, increases in respiration, heart rate, blood pressure, pupil dilation, energy mobilization, focused attention, and immunity all function in concert to promote successful fight or flight responses and improve one's chances for survival. It is important to emphasize, therefore, that stress resistance does not imply the absence of the stress response. Instead, we suggest that high levels of stress resistance delays the "tipping point" from adaptive to maladaptive responses and increase the duration and/or intensity of

\footnotetext{
(C) Informa Healthcare USA, Inc.
}

Correspondence: M. Fleshner, Department of Integrative Physiology, University of Colorado, Boulder, CO 80309-0354, USA. Tel: 303492 1483. Fax: 3034926778 . fleshner@ colorado.edu.

Declaration of interest: The authors report no conflicts of interest. The authors alone are responsible for the content and writing of the paper. 
stressor exposure needed to cross over. In other words, individuals with high levels of stress resistance are able to endure a great deal of stress before experiencing negative effects. Improving stress resilience, in contrast, facilitates recovery after stressor exposure that has crossed the "tipping point." In other words, individuals with high levels of stress resilience require less time and/or treatment to recover after experiencing the negative consequences of stressor exposure. Stress resilient organisms are capable of quickly bouncing back after crossing the "tipping point."

These definitions are conceptually distinguishable and operational in nature. Based on the above definitions, for example, an organism can express either stress resistance or stress resilience, but not both to a given stressor. This is true because stress resistance prevents the experience of negative consequences of stressor exposure, whereas, by definition, stress resilience requires one to experience the negative consequences of stressor exposure to demonstrate facilitated recovery from that experience. That same organism, however, could demonstrate stress resilience but not stress resistance to a different stressor. Although these concepts can be separated at the operational level, it remains unknown whether one can untangle them at a mechanistic (i.e. neurobiological) level. Continued research, using a variety of models such as those described below, will help in our quest to understand the underlying neurobiology of the stress-resistant brain.

Four experts presented results from studies on rodents, monkeys, and humans that exemplify unique levels of analyses and experimental approaches for investigation of the neurobiology of the stress-resistant brain. The goal of the symposium was to reveal convergence of results and facilitate understanding of neural mechanisms and intervention strategies for promoting stress resistance and stress resilience.

Monika Fleshner, (session chair and speaker; University of Colorado, Boulder, CO), gave a presentation entitled "The stress-buffering effects of exercise: neural mechanisms and health consequences." She described the evidence from both the human and animal literature that physically active organisms are resistant to the negative impact of stressor exposure on physical and mental health (Taylor et al. 1985; Brown and Siegel 1988; Dishman et al. 1998). Importantly, whether this effect is due to the stress resistance produced by exercise or the increased stress vulnerability produced by the lack of exercise in the sedentary condition remains a topic of discussion. Regardless of ones interpretation, the effects are clear. Using rodent models of physical activity, Dr Fleshner's research group has investigated the neural adaptations that occur in physically active organisms resulting in constraint of their stress responses. Physical activity status is varied by housing rats with either mobile (physically active) or locked (sedentary) running wheels in their home cages. Adult male F344 (Greenwood et al. 2005a, 2010) or Sprague Dawley (Moraska and Fleshner 2001; Greenwood et al. 2003a) rats housed with mobile wheels voluntarily run $\sim 2-3 \mathrm{~km}$ every night, have improved metabolic fitness (Kennedy et al. 2005), and display an array of stressbuffering adaptations. For example, rats that live with a running wheel for 6 weeks prior to exposure to an acute, intense stressor (i.e. uncontrollable tail shock) are protected against stress-induced (a) immunosuppression (anti-KLH antibody suppression; Moraska and Fleshner 2001), (b) inflammatory cytokines elevations (IL1- $\beta$ and TNF- $\alpha$, Speaker et al. 2011), and (c) affective dysregulation including anxiety (exaggerated freezing; Greenwood et al. 2003a, 2005b), social avoidance (decreased social exploration and unpublished observation), and learned helplessness (shuttle box escape deficit; Greenwood et al. 2003a, 2005a).

The neural mechanisms likely responsible for the stress-buffering effects of wheel running include adaptations in the central sympathetic nervous system circuit (Greenwood et al. 2003b; Fleshner 2005), the dorsal raphe serotonergic (DRN 5-HT) circuit (Greenwood et al. 
2003a, 2005b), and the nigra-striatal dopaminergic reward pathway (Greenwood et al. 2011). Together, these neural adaptations function to constrain, but not prevent (which would be maladaptive) the stress response. One example of this constraint involves the DRN 5-HT system. Sedentary rats exposed to uncontrollable, but not controllable, stress excessively activate DRN 5-HT neurons leading to 5-HT neural sensitization and learned helplessness. In contrast, physically active rats exposed to the same uncontrollable stressor respond with a constrained DRN 5-HT response. Consequently, physically active rats are protected from DRN 5-HT sensitization and learned helplessness. Evidence to date suggests that the stress-buffering effects are not due to physical activity per se because forced treadmill running produces equal or greater peripheral metabolic changes but minimal stress-buffering adaptations (Moraska et al. 2000). Instead, we propose that voluntary wheel running is ideal for boosting stress resistance because voluntary exercise increases growth factors (brain derived neurotrophic factor [BDNF], insulin-like growth factor [IGF] and nerve growth factor $[\mathrm{NGF}]$ ) and neurogenesis, which likely support the plasticity and adaptations in neural circuitry, and activates "reward" and "controllability" neurocircuitry. Moreover, wheel running or voluntary exercise is translatable to humans and produces positive side effects including body weight loss, improved cardiovascular function, and improved insulin sensitivity.

Steven F. Maier, (speaker; University of Colorado, Boulder, CO), gave a presentation entitled "The roles of behavioral control and the ventral medial prefrontal cortex in stress resistance and vulnerability." He described evidence to support the notion that the degree of behavioral control that an organism has over a stressor is arguably the most potent variable modulating the impact of the stressor yet discovered. Exposure to aversive events over which the organism has no behavioral control produces a constellation of behavioral and neurochemical changes that do not occur if some aspect of the stressor can be controlled by behavioral responses, a phenomenon that has been labeled "learned helplessness" and "behavioral depression" (Maier and Watkins 2010). Earlier work exploring the mechanism(s) underlying this phenomenon focused on understanding how stressors produce the consequences they do when they are uncontrollable. Maier's work has implicated 5-HT neurons in the caudal DRN as a key feature of the behavioral consequences of uncontrollable stress. Briefly, uncontrollable, relative to controllable, stressors lead to an intense activation of DRN 5-HT neurons, producing sensitization of these neurons for a period of time. Thus, input to the DRN during the period of sensitization, as occurs during behavioral testing, leads to an exaggerated release of 5-HT in projection regions, the proximal cause of the behavioral changes (Christianson et al. 2010).

However, research has recently shifted to an exploration of the "other side of the coin," namely how the presence of behavioral control blunts the impact of the stressor being experienced and blocks the impact of subsequent stressors, even if they are uncontrollable (so-called "behavioral immunization"). It had previously been assumed that control is not an active process, but is merely the absence of actively "learning about uncontrollability." Here, evidence is presented that having control is the active factor; in that having control suppresses the neural activation produced by the stressor. Research is reviewed which indicates that control produces resistance to the effects of (a) contemporaneous stressors because it activates ventral medial prefrontal cortical (vmPFC) inhibitory control over stress-responsive brainstem and limbic structures that include the DRN (Amat et al. 2005) and (b) later occurring stressors because it produces a long-lasting alteration of the vmPFC such that even uncontrollable stressors now lead to vmPFC-mediated inhibition of stressresponsive structures during the stressor (Amat et al. 2006). This engagement of vmPFC circuitry does not extend to all conditions that produce stressor resistance. For example, the presence of safety signals reduces stressor impact, but this effect depends on the insular cortex rather than the vmPFC (Christianson et al. 2008). 
David M. Lyons, (speaker; Stanford University, Stanford, CA), gave a presentation entitled "Stress buffering mechanisms in nonhuman primates." Lyons described how coping with stress is an essential aspect of living in complex social environments. Coping tends to buffer or diminish the deleterious effects of stress and is thought to induce neuroadaptations in corticolimbic brain systems (Katz et al. 2009; Lyons et al. 2009). To test this hypothesis, Lyons and colleagues recently examined whether stress coping stimulates hippocampal neurogenesis in male adult squirrel monkeys housed in conditions enriched with intermittent social separations and new pair formations. These manipulations simulate conditions that typically occur in male social associations because of competition for limited access to residency in mixed-sex groups (Boinski et al. 2005).

With evidence of coping, initial studies confirmed that plasma cortisol levels increase and then return to prestress levels within several days of each intermittent separation and new pair formation (Karssen et al. 2007). Follow-up studies with exogenous cortisol further established that feedback regulation of the hypothalamic-pituitary-adrenal axes is not impaired (Lyons et al. 2007). More recently, Lyons and colleagues discovered that coping in conditions enriched with intermittent social separations and new pair formations increased hippocampal neurogenesis in squirrel monkey males (Lyons et al. 2010). Hippocampal neurogenesis in rodents contributes to spatial learning performance and in monkeys spatial learning was enhanced in stress coping conditions that increased hippocampal neurogenesis. Corresponding changes were discerned in the expression of genes involved in survival and integration of adult-born granule cells into functional neural circuits (Lyons et al. 2010).

These findings support the suggestion that stress coping induces neuroadaptations in corticolimbic brain regions involved in cognitive and neuroendocrine aspects of emotion regulation. Although stress generally inhibits proliferation of new cells, and thereby decreases neurogenesis in the hippocampus, coping in conditions enriched with novelty and complexity appears to override the suppressive effects of stress on hippocampal neurogenesis. Psychotherapies designed to promote stress coping in humans with depressive disorders may potentially have similar effects, but the neurogenic potential of stress coping has not been examined in clinical neuroscience research.

Murray Raskind, (speaker; University of Washington, Seattle, WA), gave a presentation entitled "Noradrenergic-based treatment strategies for post-traumatic stress disorder (PTSD)." Increased responsiveness to norepinephrine at brain $\alpha 1$ adrenoreceptors (AR) likely contributes to the pathophysiology of PTSD (Pellejero et al. 1984; Southwick et al. 1993; Mellman et al. 1995; Vythilingam et al. 2000). Such increased $\alpha 1$ AR responsiveness promotes release of the anxiogenic neuropeptide corticotropin releasing factor (CRF), disrupts rapid eye movement (REM) sleep, and enhances fight or flight cognition (Birnbaum et al. 1999). Pharmacologic blockade of central nervous system (CNS) $\alpha_{1}$ AR, therefore, is a rational approach to PTSD treatment. Prazosin is a clinically available $\alpha 1$ AR antagonist that crosses the blood-brain barrier and has been demonstrated to block CNS $\alpha_{1}$ AR when administered peripherally (Menkes et al. 1981). This inexpensive generic drug is the only clinically available $\alpha 1$ AR antagonist that easily accesses the CNS.

Raskind's group has conducted three placebo-controlled clinical trials of prazosin for PTSD. The first two were on Vietnam War Veterans with severe PTSD trauma nightmares and sleep disruption (Raskind et al. 2003, 2007). Prazosin was significantly and substantially more effective than placebo for target nighttime PTSD symptoms as well as for daytime sense of well-being and ability to function. The third study in civilian trauma PTSD was equally positive for PTSD symptoms and demonstrated 94 min longer total sleep time with prazosin than with placebo (Taylor et al. 2008). Prazosin remains effective for years when taken chronically. Two large multicenter clinical trials of prazosin for PTSD are currently 
under process sponsored by the Department of Veterans Affairs and the Department of Defense. Other emerging uses of prazosin in stress-related disorders supported by positive placebo-controlled pilot studies are for disruptive agitation in Alzheimer's disease (Wang et al. 2009) and maintenance of sobriety in alcohol dependence (Simpson et al. 2009).

\section{Summary}

Understanding the mechanisms involved in promoting stress resistance (increasing the duration and/or intensity of stressor required to cross the "tipping point" from adaptive to maladaptive responses) and stress resilience (facilitating recovery after crossing the "tipping point") is an important area of inquiry for stress researchers. Clearly, crossing the "tipping point" can result in devastating clinical mood disorders such as anxiety, depression, and PTSD. Work presented here suggests that pharmacological treatments (Prazosin) can help reduce symptoms and may facilitate recovery. Our ability to "fix" the broken mind, however, is limited. Thus, improving stress resistance to prevent damage would be optimal. The work presented in these symposia reveals several behavioral and environmental manipulations capable of promoting stress resistance and/or resilience. Prior experience with behavioral control, exercise, and new pairings and group separations, all produce stressbuffering effects. Each manipulation produces neural adaptations that may be critical for evoking increases in stress resistance and stress resilience. Such neural adaptations could involve newly recognized mechanisms of gene regulation that includes transcriptional plasticity and epigenetic modifications. The results presented here suggest that altering specific behavioral and environmental factors can improve our ability to successfully cope with life's stressors.

\section{References}

Amat J, Baratta MV, Paul E, Bland ST, Watkins LR, Maier SF. Medial prefrontal cortex determines how stressor controllability affects behavior and dorsal raphe nucleus. Nat Neurosci. 2005; 8:365371. [PubMed: 15696163]

Amat J, Paul E, Zarza C, Watkins LR, Maier SF. Previous experience with behavioral control over stress blocks the behavioral and dorsal raphe nucleus activating effects of later uncontrollable stress: Role of the ventral medial prefrontal cortex. J Neurosci. 2006; 26:13264-13272. [PubMed: 17182776]

Birnbaum S, Gobeske KT, Auerbach J, Taylor JR, Arnsten AF. A role for norepinephrine in stressinduced cognitive deficits: Alpha-1-adrenoceptor mediation in the prefrontal cortex. Biol Psychiatry. 1999; 46:1266-1274. [PubMed: 10560032]

Boinski S, Kauffman L, Ehmke E, Schet S, Vreedzaam A. Dispersal patterns among three species of squirrel monkeys (Saimiri oestedii, S. boliviensis, and S. sciureus): I. Divergent costs and benefits. Behaviour. 2005; 142:525-632.

Brown JD, Siegel JM. Exercise as a buffer of life stress: A prospective study of adolescent health. Health Psychol. 1988; 7:341-353. [PubMed: 3168979]

Christianson JP, Benison AM, Jennings J, Sandsmark EK, Amat J, Kaufman RD, Baratta MV, Paul ED, Campeau S, Watkins LR, Barth DS, Maier SF. The sensory insular cortex mediates the stressbuffering effects of safety signals but not behavioral control. J Neurosci. 2008; 28:13703-13711. [PubMed: 19074043]

Christianson JP, Ragole T, Amat J, Greenwood BN, Strong PV, Paul ED, Fleshner M, Watkins LR, Maier SF. 5-Hydroxytryptamine $2 \mathrm{C}$ receptors in the basolateral amygdala are involved in the expression of anxiety after uncontrollable traumatic stress. Biol Psychiatry. 2010; 67:339-345. [PubMed: 19914601]

Dishman RK, Bunnell BN, Youngstedt SD, Yoo HS, Mougey EH, Meyerhoff JL. Activity wheel running blunts increased plasma adrenocorticotrophin (ACTH) after footshock and cage-switch stress. Physiol Behav. 1998; 63:911-917. [PubMed: 9618016] 
Fleshner M. Physical activity and stress resistance: Sympathetic nervous system adaptations prevent stress-induced immunosuppression. Exerc Sport Sci Rev. 2005; 33:120-126. [PubMed: 16006819]

Greenwood BN, Foley TE, Day HE, Campisi J, Hammack SH, Campeau S, Maier SF, Fleshner M. Freewheel running prevents learned helplessness/behavioral depression: Role of dorsal raphe serotonergic neurons. J Neurosci. 2003a; 23:2889-2898. [PubMed: 12684476]

Greenwood BN, Kennedy S, Smith TP, Campeau S, Day HE, Fleshner M. Voluntary freewheel running selectively modulates catecholamine content in peripheral tissue and c-Fos expression in the central sympathetic circuit following exposure to uncontrollable stress in rats. Neuroscience. 2003b; 120:269-281. [PubMed: 12849759]

Greenwood BN, Foley TE, Burhans D, Maier SF, Fleshner M. The consequences of uncontrollable stress are sensitive to duration of prior wheel running. Brain Res. 2005a; 1033:164-178. [PubMed: 15694921]

Greenwood BN, Foley TE, Day HE, Burhans D, Brooks L, Campeau S, Fleshner M. Wheel running alters serotonin (5-HT) transporter, 5-HT1A, 5-HT1B, and alpha 1b-adrenergic receptor mRNA in the rat raphe nuclei. Biol Psychiatry. 2005b; 57:559-568. [PubMed: 15737672]

Greenwood BN, Foley TE, Le TV, Strong PV, Loughridge AB, Day HE, Fleshner M. Long term voluntary wheel running is rewarding and produces plasticity in the mesolimbic reward pathway. Behav Brain Res. 2011; 217:354-362. [PubMed: 21070820]

Karssen AM, Her S, Li JZ, Patel PD, Meng F, Bunney WE Jr, Jones EG, Watson SJ, Akil H, Myers RM, Schatzberg AF, Lyons DM. Stress-induced changes in primate prefrontal profiles of gene expression. Mol Psychiatry. 2007; 12:1089-1102. [PubMed: 17893703]

Katz M, Liu C, Schaer M, Parker KJ, Ottet MC, Epps A, Buckmaster CL, Bammer R, Moseley ME, Schatzberg AF, Eliez S, Lyons DM. Prefrontal plasticity and stress inoculation-induced resilience. Dev Neurosci. 2009; 31:293-299. [PubMed: 19546566]

Kennedy SL, Smith TP, Fleshner M. Resting cellular and physiological effects of freewheel running. Med Sci Sports Exerc. 2005; 37:79-83. [PubMed: 15632672]

Lyons DM, Parker KJ, Zeitzer JM, Buckmaster CL, Schatzberg AF. Preliminary evidence that hippocampal volumes in monkeys predict stress levels of adrenocorticotropic hormone. Biol Psychiatry. 2007; 62:1171-1174. [PubMed: 17573043]

Lyons DM, Parker KJ, Katz M, Schatzberg AF. Developmental cascades linking stress inoculation, arousal regulation, and resilience. Front Behav Neurosci. 2009; 3:1-6. [PubMed: 19194528]

Lyons DM, Buckmaster PS, Lee AG, Wu C, Mitra R, Duffey LM, Buckmaster CL, Her S, Patel PD, Schatzberg AF. Stress coping stimulates hippocampal neurogenesis in adult monkeys. Proc Natl Acad Sci USA. 2010; 107:14823-14827. [PubMed: 20675584]

Maier SF, Watkins LR. Role of the medial prefrontal cortex in coping and resilience. Brain Res. 2010; 1355:52-60. [PubMed: 20727864]

Mellman TA, Kumar A, Kulick-Bell R, Kumar M, Nolan B. Nocturnal/daytime urine noradrenergic measures and sleep in combat-related PTSD. Biol Psychiatry. 1995; 38:174-179. [PubMed: 7578660]

Menkes DB, Baraban JM, Aghajanian GK. Prazosin selectively antagonizes neuronal responses mediated by alpha1-adrenoceptors in brain. Naunyn Schmiedebergs Arch Pharmacol. 1981; 317:273-275. [PubMed: 6119624]

Moraska A, Fleshner M. Voluntary physical activity prevents stress-induced behavioral depression and anti-KLH antibody suppression. Am J Physiol Regul Integr Comp Physiol. 2001; 281:R484-R489. [PubMed: 11448851]

Moraska A, Deak T, Spencer RL, Roth D, Fleshner M. Treadmill running produces both positive and negative physiological adaptations in Sprague-Dawley rats. Am J Physiol Regul Integr Comp Physiol. 2000; 279:R1321-R1329. [PubMed: 11004000]

Pellejero T, Monti JM, Baglietto J, Jantos H, Pazos S, Cichevski V, Hawkins M. Effects of methoxamine and alpha-adrenoceptor antagonists, prazosin and yohimbine, on the sleep-wake cycle of the rat. Sleep. 1984; 7:365-372. [PubMed: 6515252]

Raskind MA, Peskind ER, Kanter ED, Petrie EC, Radant A, Thompson CE, Dobie DJ, Hoff D, Rein RJ, Straits-Troster K, Thomas RG, McFall MM. Reduction of nightmares and other PTSD 
symptoms in combat veterans by prazosin: A placebo-controlled study. Am J Psychiatry. 2003; 160:371-373. [PubMed: 12562588]

Raskind MA, Peskind ER, Hoff DJ, Hart KL, Holmes HA, Warren D, Shofer J, O'Connell J, Taylor F, Gross C, Rohde K, McFall ME. A parallel group placebo controlled study of prazosin for trauma nightmares and sleep disturbance in combat veterans with post-traumatic stress disorder. Biol Psychiatry. 2007; 61:928-934. [PubMed: 17069768]

Simpson TL, Saxon AJ, Meredith CW, Malte CA, McBride B, Ferguson LC, Gross CA, Hart KL, Raskind M. A pilot trial of the alpha-1 adrenergic antagonist, prazosin, for alcohol dependence. Alcohol Clin Exp Res. 2009; 33:255-263. [PubMed: 18945226]

Southwick SM, Krystal JH, Morgan CA, Johnson D, Nagy LM, Nicolaou A, Heninger GR, Charney DS. Abnormal noradrenergic function in posttraumatic stress disorder. Arch Gen Psychiatry. 1993; 50:266-274. [PubMed: 8466387]

Speaker K, Greenwood BN, Serebrakian A, Fleshner M. Regular, moderate exercise attennates the stress-induced increase in plasma IL-1 $\mathrm{B}$ but not $\mathrm{TNF}_{2}$, IL-6, IL-1D or lorticosterone. ISEI. 2011:24.

Taylor CB, Sallis JF, Needle R. The relation of physical activity and exercise to mental health. Public Health Rep. 1985; 100:195-202. [PubMed: 3920718]

Taylor FB, Martin P, Thompson C, Williams J, Mellman TA, Gross C, Peskind ER, Raskind MA. Prazosin effects on objective sleep measures and clinical symptoms in civilian trauma posttraumatic stress disorder: A placebo-controlled study. Biol Psychiatry. 2008; 63:629-632. [PubMed: 17868655]

Vythilingam M, Anderson GM, Owens MJ, Halaszynski TM, Bremner JD, Carpenter LL, Heninger GR, Nemeroff CB, Charney DS. Cerebrospinal fluid corticotropin-releasing hormone in healthy humans: Effects of yohimbine and naloxone. J Clin Endocrinol Metab. 2000; 85:4138-4145. [PubMed: 11095445]

Wang LY, Shofer JB, Rohde K, Hart KL, Hoff DJ, McFall YH, Raskind MA, Peskind ER. Prazosin for the treatment of behavioral symptoms in patients with Alzheimer disease with agitation and aggression. Am J Geriatr Psychiatry. 2009; 17:744-751. [PubMed: 19700947] 